\title{
Effects of date fruit (Phoenix dactylifera L.) on labor and delivery outcomes: a systematic review and meta-analysis
}

\author{
Alireza Bagherzadeh Karimi ${ }^{1}$, Asghar Elmi ${ }^{2 *}$, Mojgan Mirghafourvand ${ }^{1,3}$ and Roghaiyeh Baghervand Navid
}

\begin{abstract}
Background: The rate of cesarean section is increasing in all over the world with different drafts in various countries. This growth increases unpleasant outcomes of delivery. Recent studies explained the benefits of date palm fruit on labor process improvement. Date fruit can be considered as a factor for increasing vaginal delivery and also reducing the frequency of caesarean section in order to prevent its great complications. This systematic review has been designed to review clinical studies that investigate the effects of date palm fruit on labor outcomes (duration of labor stages, bishop score, and frequency of cesarean section) compared with routine cares.

Methods: This study was performed in 2019. Required data has been collected from electronic databases and manual searches. All randomized clinical trials evaluating the effects of date palm fruit on labor and delivery that were published from January 2000 to August 2019 in English and Persian languages, were incorporated in this systematic review. The methodological quality of the included studies was evaluated according to the risk of bias assessment of Cochrane handbook of systematic reviews, and were then reported using Preferred Reporting Items for Systematic Reviews and Meta-Analysis (PRISMA) statement.
\end{abstract}

Results: Eight studies were included in the qualitative and quantitative synthesis. Meta-Analysis showed that date fruit consumption can significantly reduce active phase of labor (three trials with 380 participants; (MD $=-109.3$, $\left.95 \% \mathrm{Cl}\left(-196.32,-22.29 ; I^{2}=89 \%\right), P=0.01\right)$, and also it can significantly improve the bishop score (two trials with 320 participants; $\left.\mathrm{MD}=2.45,95 \% \mathrm{Cl}\left(1.87,3.04 ; I^{2}=0 \%\right), P<0.00001\right)$. Date fruit consumption had no effects on the duration of first, second, and third stages of labor, and the frequency of cesarean section.

Conclusion: Date can reduce the duration of active phase and improve the bishop score; however, due to from the low to mediate quality of the studies; it seems that the other studies are needed to prove these results better than this.

Keywords: Date palm, Date fruit, Phoenix dactiylifera, Delivery, Labor, Systematic review, Meta-analysis

\footnotetext{
* Correspondence: maralan-bagherzadeh@hotmail.com

${ }^{2}$ School of Medicine, Tabriz University of Medical Sciences, Tabriz, Iran

Full list of author information is available at the end of the article
}

(c) The Author(s). 2020 Open Access This article is licensed under a Creative Commons Attribution 4.0 International License, which permits use, sharing, adaptation, distribution and reproduction in any medium or format, as long as you give appropriate credit to the original author(s) and the source, provide a link to the Creative Commons licence, and indicate if changes were made. The images or other third party material in this article are included in the article's Creative Commons licence, unless indicated otherwise in a credit line to the material. If material is not included in the article's Creative Commons licence and your intended use is not permitted by statutory regulation or exceeds the permitted use, you will need to obtain permission directly from the copyright holder. To view a copy of this licence, visit http://creativecommons.org/licenses/by/4.0/ The Creative Commons Public Domain Dedication waiver (http://creativecommons.org/publicdomain/zero/1.0/) applies to the data made available in this article, unless otherwise stated in a credit line to the data. 


\section{Background}

\section{Delivery and its process}

Since 1970 A. D, rate of caesarean section has increased in countries with high income. However, this rate in middle to low income countries increases with a specific rising draft $[1,2]$. This increase is significant in developing countries such as Iran with the caesarean section rate of $48 \%$. This prevalence rate is much more than global rate [3]. The growth of caesarean section rate increases unpleasant outcomes of delivery and neonatal complications such as respiratory distress syndrome, transient tachypnea of newborn and increased NICU admission [4, 5]. WHO (World Health Organization) has unnecessary announced the rate of caesarean section higher than $15 \%$ [4]. A few factors have led to the growth of caesarean section such as repeated caesarean, high maternal age in pregnancy, pregnancy with IVF (In vitro fertilization) or IUI (Intra uterine insemination), pregnancy after recurrent abortions, desire of physicians to caesarean section, and this belief that the prolapsed uterus and frequency do not occur after caesarean section [6-10]. Abnormal progress of labor and ineffective contractions of uterus are identified as two common reasons of caesarean section $[11,12]$.

According to the WHO, normal birth can be defined as:" spontaneous in onset, low-risk at the start of labor, and remaining so throughout labor and delivery. The infant is spontaneously born in the vertex position between 37 and 42 completed weeks of pregnancy" [13] There will be different methods for labor induction if the progress of labor is not appropriate, which are used alone or in combination together similar to the strip of membranes and the usage of prostaglandins or oxytocin. These methods accelerate the labor progress and decrease the caesarean section frequency [14]. Nevertheless, a review study conducted on Cochrane explained that the pregnant women are not satisfied about their labor because of the difficulties of labor [15]. Most recently, the researchers have been paying attention to remove labor difficulties, and following that, to reduce the caesarean section frequency $[16,17]$. Pregnant women need energy during labor; therefore the amount of required energy for active phase of labor should be 50-100 kcal (Kilo calories) [16, 17]. The drinking and eating are prohibited for pregnant women during labor in hospitals. It is important to know that it will lead to energy reducing, fatigue, and lack of cooperation in pregnant women, and finally could result in reducing the beneficial effects on mother and infant outcomes $[12,18,19]$. Scheepers et al. showed that the consumption of carbohydrate during labor can reduce the rate of augmented labor and decrease abnormal progress of labor [20].

\section{Date and its role in the labor}

Among the studied sugars, is the date palm fruit; which is known as the scientific name of Phoenix dactylifera L. Date fruit contains different vitamins (riboflavin, biotin, thiamin, folic acid, and ascorbic acid), higher percentage of sugar and carbohydrates, proteins, fatty acids, salt and minerals such as potassium and magnesium [21, 22]. Date fruit due to energy production and having enough calories, can be helpful for pregnant women during labor, and it can also prevent physical weakness [23-25]. Furthermore, because it contains sugar, it is fast in digestion and absorption [25]. In addition to generating energy, date fruit also contains necessary and unnecessary fatty acids that can produce prostaglandins playing an important role in cervix ripening, acceleration of delivery progress, increase of uterine contractions, and inducing labor $[26,27]$. In addition, date fruit contains any hormones that prepare uterine to stretching and child birth [28]. Also, date can accelerate labor process, increase cervix dilatation, and reduce the need for induction [23, 24]. Moreover, date in Traditional Persian Medicine (TPM) has been mentioned as a facilitator medicinal food for labor [29]. TPM is an ancient medical system and one of the important complementary and alternative medicines that has been utilized in Iran, India, and the middle east from ancient eras up to now [30, 31]. Nevertheless, there are few studies supporting the relationship between labor and date.

Most recently, a systematic review conducted on the effects of date fruit on pregnancy and delivery has been published [32]; however, there are some differences between its reviewed outcomes and this study. Therefore in that study the reporting bias and publication bias have not been regarded in inclusion of studies to meta-analysis. Accordingly this reason can cause wrong changes in meta-analysis results.

Due to the studies conducted on the benefits of date palm fruit on labor process improvement, date can be considered as a factor for increasing vaginal delivery and reducing the frequency of caesarean section in order to prevent its great complications. This systematic review aimed to review clinical studies that investigate the effects of date palm fruit on labor outcomes (duration of labor stages, bishop score, and frequency of cesarean section) compared to routine cares.

\section{Methods}

This systematic review and meta-analysis was reported according to Preferred Reporting Items for Systematic Reviews and Meta-Analysis (PRISMA) statement. This systematic review was not registered on PROSPERO. 


\section{Eligibility criteria}

\section{Inclusion and exclusion criteria of studies}

All clinical trials including randomized and quasirandomized, evaluating the effects of date palm fruit on labor and delivery that have been published from 2000 until August 2019 in English and Persian languages were included in this systematic review. Also, non-randomized clinical trials, editorials, reviews, books, case reports, case series, letter to editors, qualitative studies, and short communications were excluded. There was no limitation for the length of follow-up or treatment.

\section{Inclusion criteria (PICOS format)}

1) Participants: all pregnant women in 36-42 weeks of pregnancy with no restrictions on patient's age, nationality, and the number of parity without any serious complication.

2) Interventions: consumption of date (fruit or extract) without restriction in the number of the fruit and the duration of intervention.

3) Controls: The routine cares of pregnant women.

4) Outcomes: The primary outcomes were the duration of labor stages and the secondary outcomes were the frequency of caesarian section and bishop score.

5) Study type: Randomized and quasi-randomized clinical trials.

\section{Search strategy}

This systematic review was performed in 2019 and the last search was conducted in August 2019. Data have been collected from the databases such as PubMed, Scopus, Web of Knowledge, Clinical Keys, Embase, Google Scholar Search Engine, Scientific Information Database (SID), and IRCT (Iranian Registry of Clinical Trials) to search the relevant articles published from January 2000 to August 2019 using the keywords Phoenix dactylifera, date palm, date fruit, labor, and delivery. Also, manual search of the reliable journal data-bases was accomplished, and the references in all review articles were checked for additional related articles. To search for unpublished articles (grey literature), European Association for Grey Literature Exploitation (EAGLE) and Health Care Management Information Consortium (HMIC) were investigated. The search strategy for PubMed is available in Appendix 1 (see Additional file 1). Investigated data was transferred to Endnote software.

\section{Study selection}

The selected studies extracted from the databases by Endnote software, were independently evaluated by two authors (AE and RBN). Disagreements between them were referred to the third inspector (MM). At first, the titles of all papers were reviewed and inconsistent studies with the objectives of the study were excluded from the study. In the next step, abstract of chosen studies were reviewed and incompatible studies were excluded. Then, full texts of chosen studies were extracted. In the last stage, full-text articles were surveyed to exclude those that did not match with the inclusion criteria and the study aims. The authors elicited data from all eligible studies and registered the elicited data in the appropriate forms. Data for the primary objective of the review was gathered from the full text of each paper consisting of the trial name, year of publication, study design, sample size, participants, intervention protocol, used parts of plant, comparisons, results, and other characteristics.

\section{Assessment of risk of Bias}

The methodological quality of the included studies and their risk of bias were independently evaluated by two reviewers (MM, ABK) using RevMan 5.3.0 software, in terms of the risk of bias assessment of the Cochrane handbook. The assessment criteria consisted of seven items as follows: Selection bias (allocation concealment); Selection bias (random sequence generation); Performance bias (blinding of participants and personnel); Detection bias (blinding of outcome assessors); Attrition bias (dropouts and exclusion addressing and intention to treat analysis); Reporting bias (selective or nonselective reporting); Other bias (registration of protocol, conflict of interest declaration, ethical criteria, inclusion and exclusion criteria, sample size calculating, and funding sources declaration). Each study was evaluated as High, Low, or Unclear risk of bias for each item. Any disagreements between the two reviewers were resolved by discussion with the corresponding author. Because the number of included studies in meta-analysis was lower than 10 studies, the graphical or statistical methods were not used to evaluate publication bias.

\section{Statistical analysis}

The results of the studies were analyzed using "Review Manager" software (RevMan 5.3.0 provided by Cochrane Collaboration). The types of intervention in included studies were similar. We integrated the studies according to the types of outcomes (labor phases duration, frequency of caesarian section, and bishop score). We included all the intended outcomes of the different reports of each trial to the meta-analyses once. Dichotomous data were summarized as risk ratio (RR), and continuous data as mean difference (MD). Heterogeneity between the studies was evaluated using $\mathrm{X}^{2}$ (chi-squared) test and $\mathrm{I}^{2}$ statistic. $\mathrm{I}^{2}$ 
was used to assess heterogeneity between studies with $\geq 75 \%, 25-75$, and $<25 \%$ which were considered as high, moderate, and low heterogeneity, respectively, to indicate a substantial heterogeneity. 95\% CI was calculated, and due to the small number of included studies and low power of chi-square test for heterogeneity (in terms of the Cochrane handbook for systematic reviews of interventions), $p<0.1$ was regarded as significant. Based on the results, sensitivity analysis and subgroup analysis will be performed if needed.

\section{Results}

\section{General characteristics}

We gathered 1531 studies from databases and other hand search sources. Eight of 1531 studies (Eight fulltext papers under six trials) had eligibility criteria and were included in qualitative and quantitative analysis [33-40]. Three of them had the same ethic code (910732) (approval code of research ethics committee) and were different reports of one trial [33-35]. Also two other studies were similar and were different reports of one trial [36, 37]. We included all different outcomes (which considered in our systematic review) of the different reports of each trial to the metaanalysis (if the trial had multiple reports). The flowchart of searching and inclusion process of studies is shown in Fig. 1(According to PRISMA statement). Fore of included studies had used the date palm fruit [33, 36, 39, 40], and one study had used date fruit honey [38]. Descriptions and characteristics of the reviewed studies are shown in Table 1 . No side effects were reported for date palm in any of the studies. The minimum and maximum intervention durations of founded studies were two days and four weeks, respectively. Date palm and its extracts were orally utilized in all of the studies. Sample sizes of these studies were 89 to 210 participants. 653 participants were included in the analysis, 325 participants in intervention group, and 328 in control group. Ages of participants were ranged from 20 to 40. All of

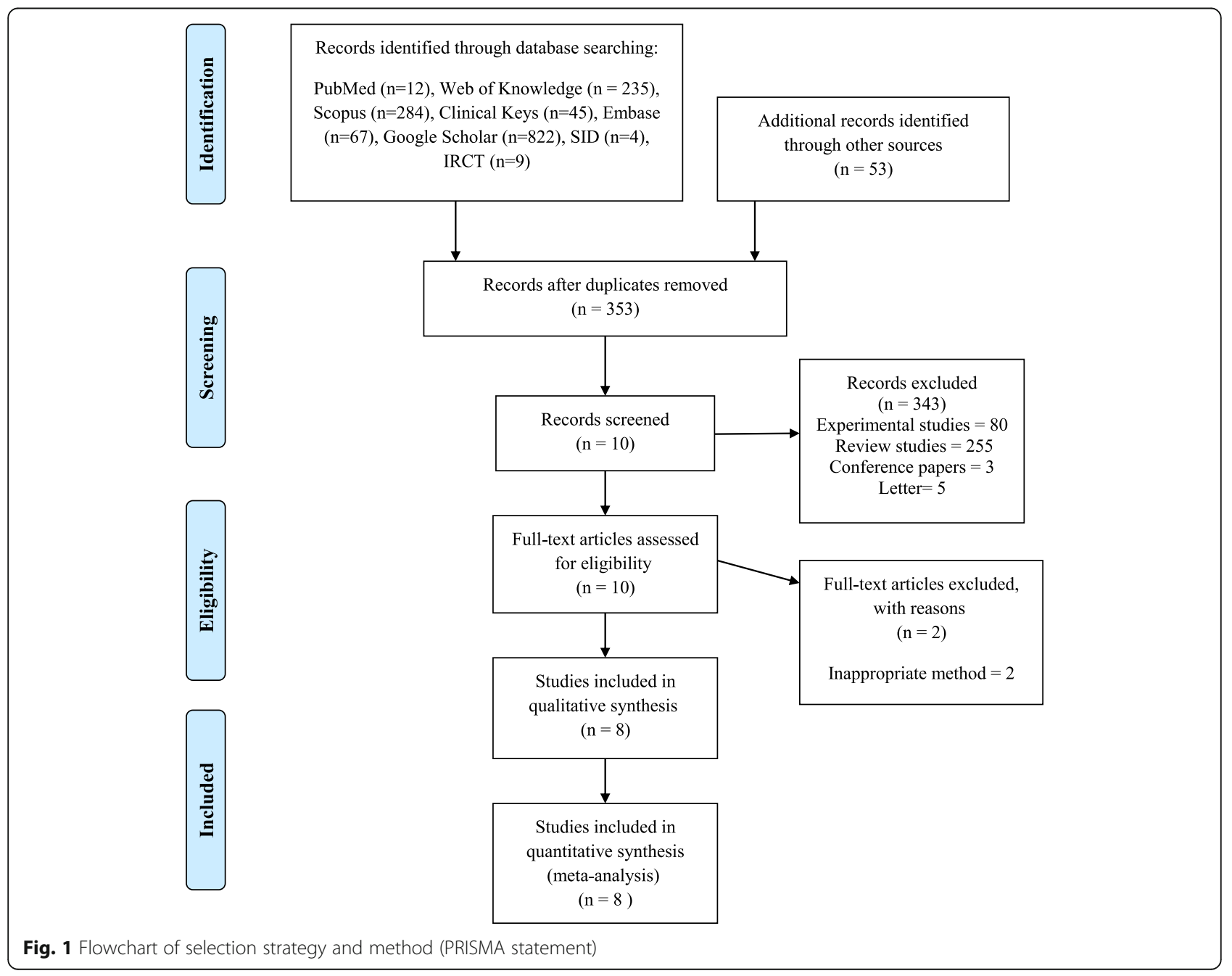




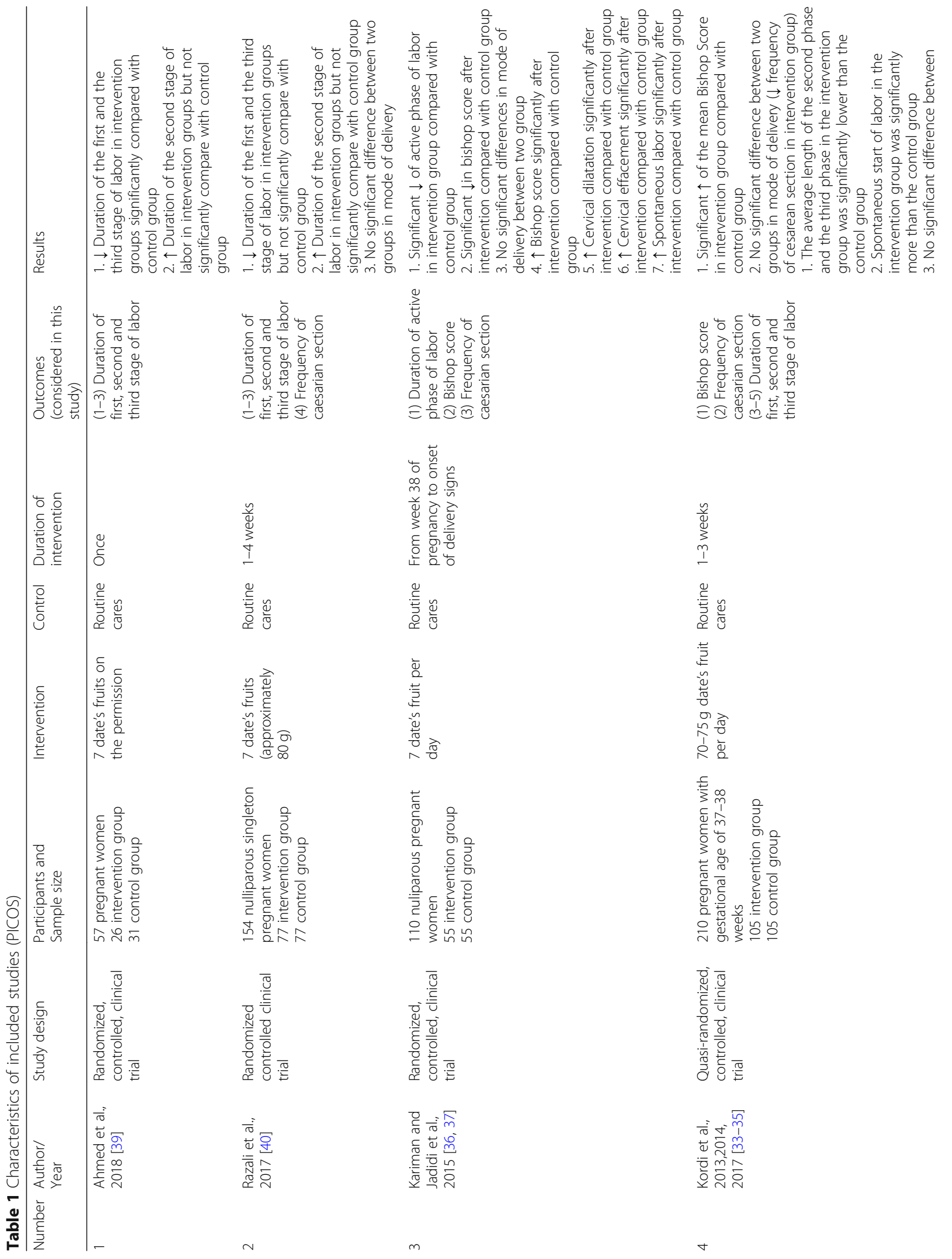




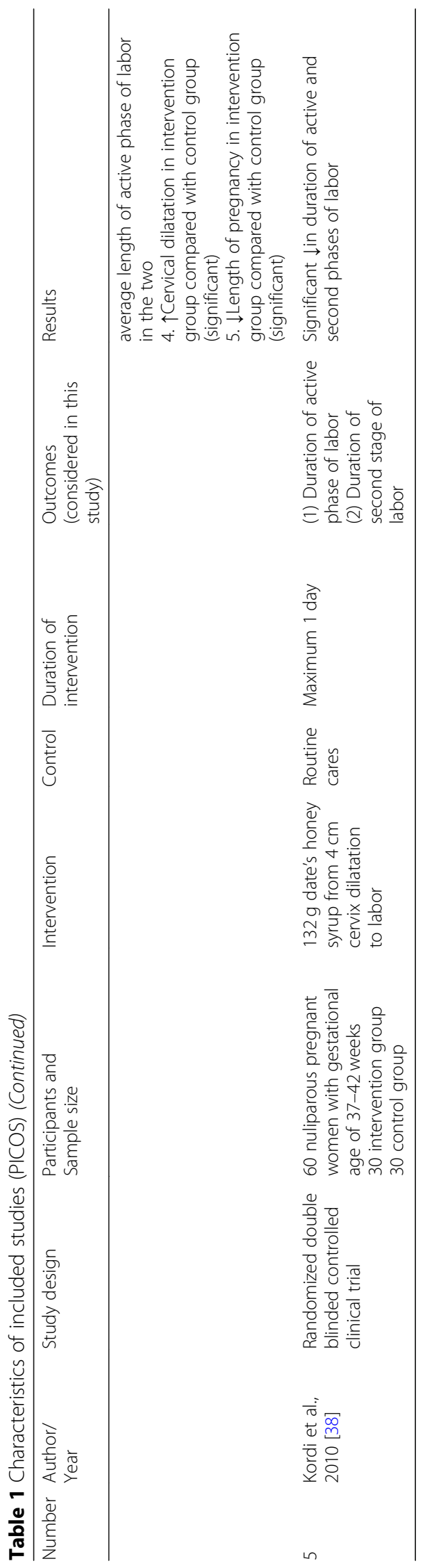




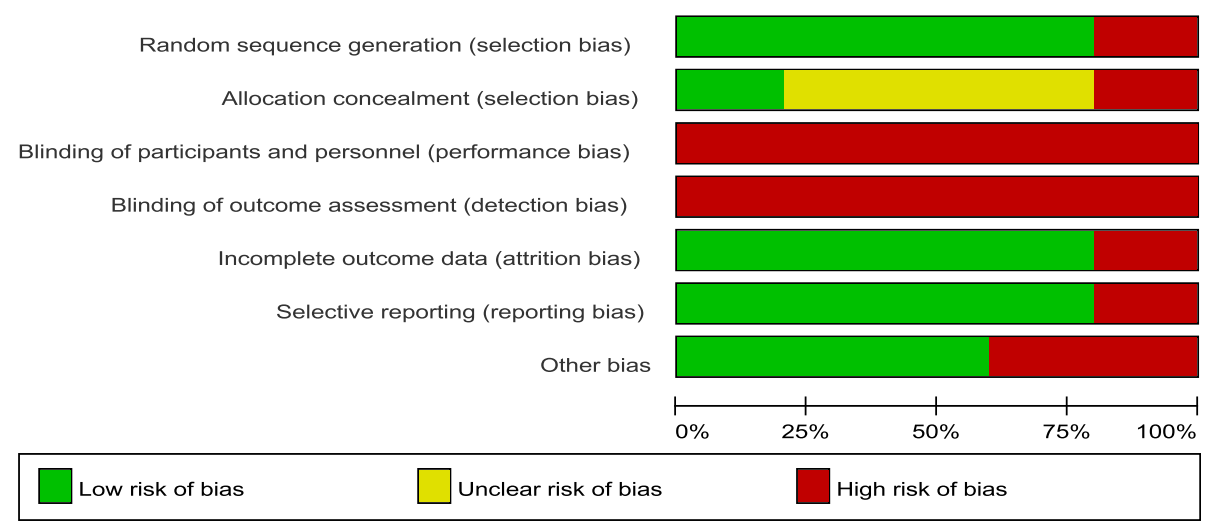

Fig. 2 Risk of bias graph

these studies had control groups consisting of placebo and routine cares in one study [38], and routine cares in other studies [33, 36, 39, 40]. However, placebo control group was not included in meta-analysis and qualitative analysis.

\section{Risk of bias within studies (Figs. 2 and 3)}

The details of risk of bias within included studies and authors judgment are listed in Table 2.

Random sequence generation Four studies of 5 studies had used random number table, random generator or computer programmed random sequencing; and thus,

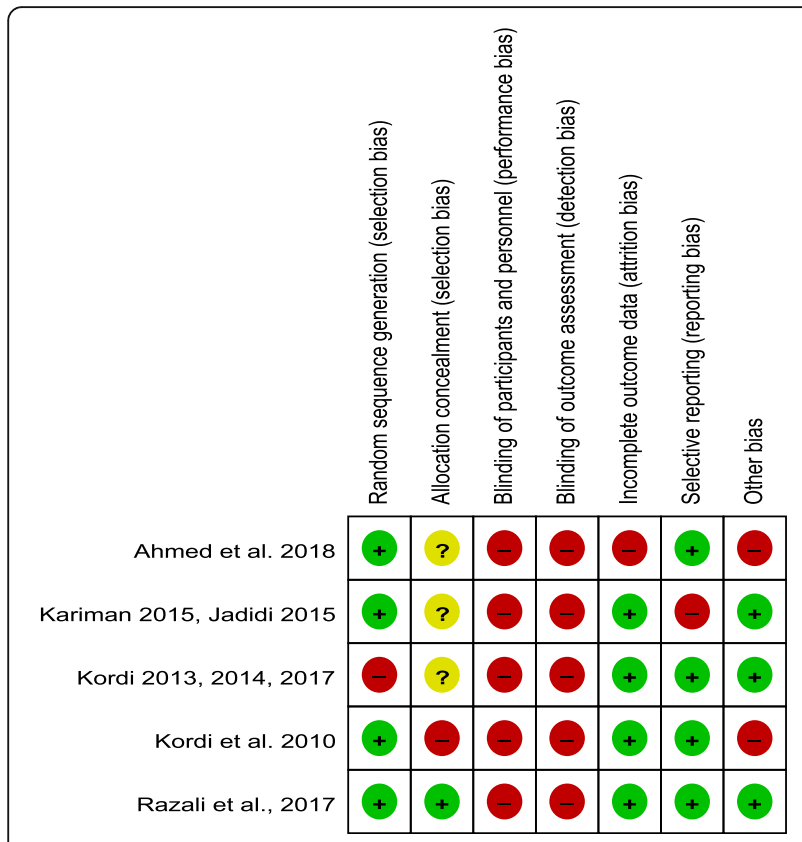

Fig. 3 Risk of bias summary they were rated as low risk of bias. Another study used no reliable randomization method and was evaluated as high risk of bias.

Allocation concealment One study of included studies had used sealed-envelopes method to the allocation concealment and was evaluated as low risk of bias. Three trials of five included trials did not determine the method of allocation concealment, and were evaluated as unclear risk of bias. One trial had not concealment and was evaluated as high risk of bias.

Blinding of participants and personnel Due to the consumption of date fruit as intervention and routine care as control, all of the included studies had not performed blinding and were rated as high risk of bias.

Blinding of outcome assessment All of these studies were assessed as high risk of bias; because they had no evidence of blinding of outcome assessors.

Incomplete outcome data Out of 5 trials, 2 trials have mentioned the dropped out and analyzed the intention to treat, and 2 trials had no dropped out or lost to follow up; therefore they were rated as low risk of bias. Also, one study had attrition for missing participants; however, the statistical analysis was not followed by the intention to treat.

Selective reporting One study had registered protocol; but the reported outcomes did not match with registered outcomes and were given the high risk of bias. Other included studies had reported their expected outcomes and were assessed as low risk of bias. 
Table 2 Risk of bias within studies

\begin{tabular}{|c|c|c|}
\hline Bias & Authors judgment & Support for judgment \\
\hline \multicolumn{3}{|l|}{ Ahmed et al. (2018) [39] } \\
\hline Random sequence generation & Low risk & Simple random sampling has been used \\
\hline Allocation concealment & Unclear risk & No specific information \\
\hline Blinding of participants and personnel & High risk & Open label manner \\
\hline Blinding of outcome assessors & High risk & Open label manner \\
\hline Incomplete outcome data & High risk & Intention to treat analysis has not conducted. \\
\hline Selective reporting & Low risk & $\begin{array}{l}\text { Protocol is unavailable but the authors have reported thei } \\
\text { expected mentioned outcomes }\end{array}$ \\
\hline Other & High risk & $\begin{array}{l}\text { No registered protocol, sample size calculating method is } \\
\text { not specified }\end{array}$ \\
\hline \multicolumn{3}{|l|}{ Razali et al. (2017) [40] } \\
\hline Random sequence generation & Low risk & Sealed envelope numbers has been used \\
\hline Allocation concealment & Low risk & It was done using "sealed envelope" manner \\
\hline Blinding of participants and personnel & High risk & Open label manner \\
\hline Blinding of outcome assessors & High risk & Open label manner \\
\hline Incomplete outcome data & Low risk & $\begin{array}{l}\text { The dropped out has been mentioned and intention } \\
\text { to treat has been analyzed }\end{array}$ \\
\hline Selective reporting & Low risk & $\begin{array}{l}\text { Protocol is unavailable but the both primary and } \\
\text { secondary outcomes have been reported }\end{array}$ \\
\hline Other & Low risk & $\begin{array}{l}\text { Registered protocol exist, sample size calculating } \\
\text { method is specified, Ethical approval exist, Specified } \\
\text { inclusion and exclusion criteria, specified funding } \\
\text { source, no conflict of interest }\end{array}$ \\
\hline \multicolumn{3}{|l|}{ Kariman and Jadidi et al. (2015) $[36,37]$} \\
\hline Random sequence generation & Low risk & Random number generator has been used \\
\hline Allocation concealment & Unclear risk & No specific information \\
\hline Blinding of participants and personnel & High risk & Open label manner \\
\hline Blinding of outcome assessors & High risk & Open label manner \\
\hline Incomplete outcome data & Low risk & $\begin{array}{l}\text { The dropped out has been mentioned and intention } \\
\text { to treat has been analyzed }\end{array}$ \\
\hline Selective reporting & High risk & $\begin{array}{l}\text { Protocol is available but secondary outcomes have not } \\
\text { been reported }\end{array}$ \\
\hline Other & Low risk & $\begin{array}{l}\text { Registered protocol exist, sample size calculating method } \\
\text { is specified, Ethical approval exist, Specified inclusion and } \\
\text { exclusion criteria, specified funding source, no conflict } \\
\text { of interest }\end{array}$ \\
\hline \multicolumn{3}{|l|}{ Kordi et al.(2013, 2014, 2017) [33-35] } \\
\hline Random sequence generation & High risk & The days of the Week have been used for randomization \\
\hline Allocation concealment & Unclear risk & No specific information \\
\hline Blinding of participants and personnel & High risk & Open label manner \\
\hline Blinding of outcome assessors & High risk & Open label manner \\
\hline Incomplete outcome data & Low risk & $\begin{array}{l}\text { The dropped out has been mentioned and intention } \\
\text { to treat has been analyzed }\end{array}$ \\
\hline Selective reporting & Low risk & $\begin{array}{l}\text { Protocol is available and both primary and secondary } \\
\text { outcomes have been reported }\end{array}$ \\
\hline Other & Low risk & $\begin{array}{l}\text { Registered protocol exist, sample size calculating } \\
\text { method is specified, Ethical approval exist, Specified } \\
\text { inclusion and exclusion criteria, specified funding } \\
\text { source, no conflict of interest }\end{array}$ \\
\hline
\end{tabular}

Kordi et al. (2010) [38] 
Table 2 Risk of bias within studies (Continued)

\begin{tabular}{lll}
\hline Bias & Authors judgment & Support for judgment \\
\hline Random sequence generation & Low risk & Simple random sampling has been used \\
Allocation concealment & High risk & There was no evidence for allocation concealment \\
Blinding of participants and personnel & High risk & Open label manner \\
$\begin{array}{l}\text { Blinding of outcome assessors } \\
\text { Incomplete outcome data }\end{array}$ & High risk & Open label manner \\
Selective reporting & Low risk & There was no lost to follow up \\
Other & Low risk & Protocol is unavailable but both primary and secondary \\
& & Outcomes have been reported \\
& & Conflict of interest didn't declared, no specified \\
\end{tabular}

Other bias Three trials had registered protocol, specified funding source, appropriate ethical criteria, inclusion and exclusion criteria, specified sample size calculating method, and declaration of conflict of interest; therefore, they were rated as low risk of bias. Other trials did not have some of mentioned cases and were rated as high risk of bias.

\section{Outcomes}

We considered common outcome among the included studies in quantitative integration, included active phase of labor duration, first stage of labor duration, second stage of labor duration, and third stage of labor duration as primary outcomes; and bishop score and frequency of caesarian section as secondary outcomes. Also, we performed the sensitivity analysis, because one trial of included trials was quasirandomized study. Sensitivity analysis did not change the results of primary meta-analysis. The summary of sensitivity analysis is shown in Table 3 . The forest plots of sensitivity analyses are available in Appendix 2-6 (See Additional file 2). Moreover, we performed subgroup analysis for two subgroups (Intervention during labor, and intervention during pregnancy). The results of subgroup analysis showed significant changes in the third stage of labor meta-analysis results. The forest plots of subgroup analyses are available in Appendix 7-10 (See Additional file 3).

Active phase of labor Three trials with 380 participants were included (190 in intervention group and 190 in control group). There was moderate heterogeneity among the studies $\left(\mathrm{I}^{2}=89 \%, P=0.0002\right)$. The quantitative synthesis showed that date consumption significantly reduce the duration of active phase of labor compared with control group (MD $=-109.3$, 95\%CI $(-$ 196.32, -22.29 ), $P=0.01$ ) (Fig. 4).

First stage of labor Two studies reported the duration of first stage of labor. Totally, 211 participants were included (103 in intervention group and 108 in control group). Moderate heterogeneity accompanied $\left(\mathrm{I}^{2}=71 \%\right.$, $P=0.06)$. There was no significant difference between two groups $(\mathrm{MD}=-76.16,95 \% \mathrm{CI}(-198.51,46.18), P=$ 0.22) (Fig. 5).

Second stage of labor We collected data from 4 trials with 481 participants (238 in intervention group and 243 in control group). The heterogeneity was high $\left(\mathrm{I}^{2}=93 \%\right.$, $P<0.00001)$. There was no significant difference between two groups $(\mathrm{MD}=-6.41,95 \% \mathrm{CI}[-22.67,9.86]$, $P=0.44)$ (Fig. 6).

Table 3 The summary of sensitivity analyses

\begin{tabular}{|c|c|c|c|}
\hline Number & Measured outcome & $\begin{array}{l}\text { Meta-analyses of all studies } \\
\text { (Overall effect statistical significance) }\end{array}$ & $\begin{array}{l}\text { Sensitivity Analyses }{ }^{a} \\
\text { (Overall effect statistical significance) }\end{array}$ \\
\hline 1 & Second stage of labor & $P=0.44$ & $P=0.64$ \\
\hline 2 & Third stage of labor & $P=0.82$ & $P=0.39$ \\
\hline 3 & Active phase of labor & $P=0.01^{b}$ & $P=0.01^{b}$ \\
\hline 4 & Bishop score & $\mathrm{P}<0.00001^{\mathrm{b}}$ & $\mathrm{P}<0.00001^{\mathrm{b}}$ \\
\hline 5 & Frequency of cesarean section & $P=0.23$ & $P=0.59$ \\
\hline
\end{tabular}

aquasi-randomized study (Kordi 2013, 2014, 2017) [33-35] removed from meta-analysis

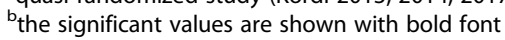




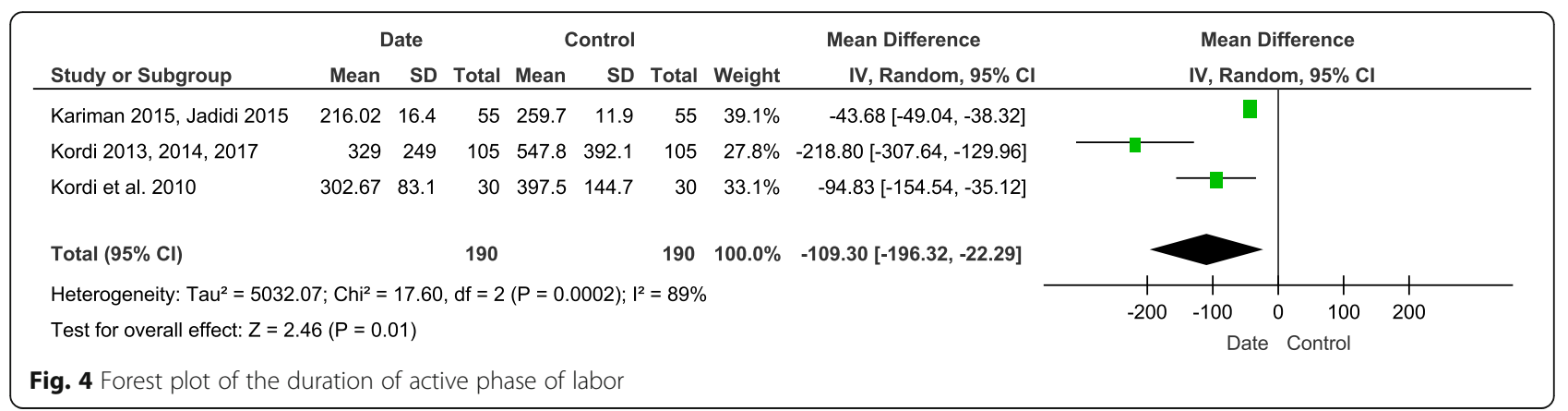

Third stage of labor Three trials with 421 participants (208 in intervention group and 213 in control group) described the duration of the third stage of labor. The intervention cannot decrease the duration of the third stage of labor $(\mathrm{MD}=0.39,95 \% \mathrm{CI}(-2.92,3.71), P=$ $0.82)$. The heterogeneity was high $\left(\mathrm{I}^{2}=89 \%, P=0.0001\right)$ (Fig. 7). The subgroup analysis showed that the intervention during pregnancy significantly reduces the duration of the third stage of labor compared with control group. (Appendix 9) (See Additional file 3).

Bishop score Two trials reported data on the bishop score with 320 participants (160 in intervention group and 160 in control group). There was no heterogeneity $\left(\mathrm{I}^{2}=0 \%, P=0.60\right)$. The intervention significantly improved the bishop score, compared to control group $(\mathrm{MD}=2.45,95 \% \mathrm{CI}(1.87,3.04), P<0.00001)$ (Fig. 8).

Frequency of caesarian section Three trials had showed the effect of intervention on frequency of caesarian section. 474 participants were included in this outcome meta-analysis (237 in intervention group and 237 in control group). Low heterogeneity was accompanied $\left(\mathrm{I}^{2}=0 \%, P=0.38\right)$. There was no significant difference between two groups. (Risk Ratio $=0.80,95 \% \mathrm{CI}(0.56$, 1.15), $P=0.23$ ) (Fig. 9).

Adverse effects No side effects have been reported in any of the included studies.

\section{Discussion}

Based on the performed searches, this is the first systematic review conducted on the effects of date on bishop score and frequency of caesarean section, and second one on the effects of date on the duration of labor stages. Meta-analysis showed that the consumption of date fruit can significantly reduce the duration of the active phase and improve the bishop score, and may reduce the frequency of cesarean section in intervention group compared to control group. Based on meta-analysis, date palm fruit consumption resulted in a significant reduction in the duration of active phase of labor compared with control group; however, it is not observed in the first, second, and the third stage of labor.

Nasiri et al. in their systematic review have achieved different results about the duration of labor stages. Those results are not reliable, because they had included three duplicated published studies in their meta-analysis. In that study, bishop score and frequency of caesarean section were not investigated [32].

Different mechanisms have been expressed on the effects of date palm on the labor process. Date palm fruit has high calorie, and is proposed as an energizer. The sugar in date fruit is glucose with simple digestion and absorption. Date fruit provides and maintains required energy for pregnant woman to prevent tiredness. It leads to normal progress of labor, due to providing continual glucose and preserving body

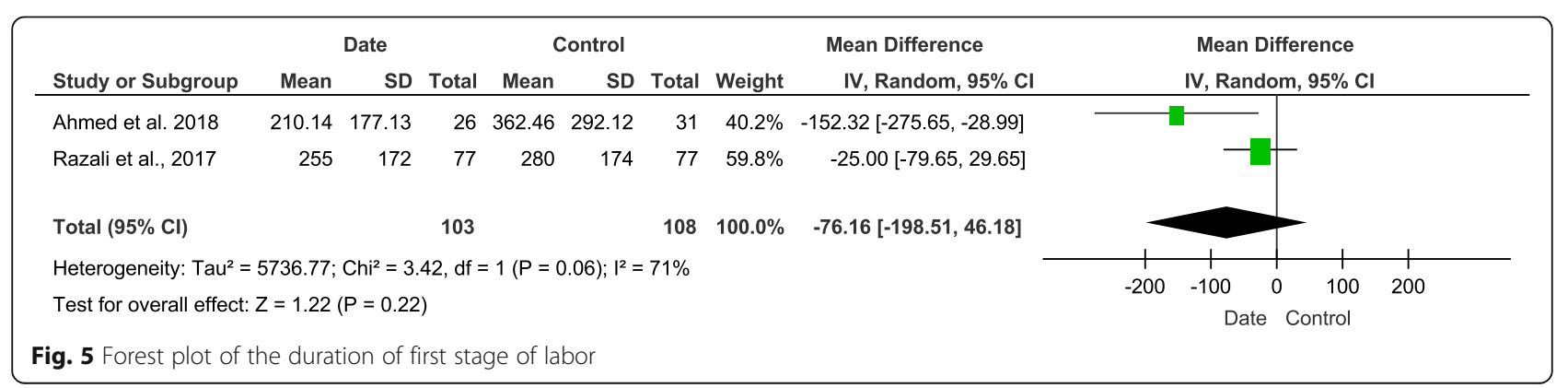




\begin{tabular}{|c|c|c|c|c|c|c|c|c|c|c|c|c|}
\hline \multirow{3}{*}{$\begin{array}{l}\text { Study or Subgroup } \\
\text { Kordi et al. } 2010\end{array}$} & \multicolumn{3}{|c|}{ Date } & \multicolumn{3}{|c|}{ Control } & \multirow[b]{2}{*}{ Weight } & \multirow{2}{*}{$\begin{array}{l}\text { Mean Difference } \\
\text { IV, Random, } 95 \% \mathrm{Cl}\end{array}$} & \multirow{2}{*}{\multicolumn{4}{|c|}{$\begin{array}{c}\text { Mean Difference } \\
\text { IV, Random, } 95 \% \mathrm{CI}\end{array}$}} \\
\hline & \multirow{2}{*}{$\begin{array}{l}\text { Mean } \\
48.33\end{array}$} & \multirow{2}{*}{$\begin{array}{r}\text { SD } \\
15.16\end{array}$} & \multirow{2}{*}{$\begin{array}{r}\text { Total } \\
30\end{array}$} & \multirow{2}{*}{$\begin{array}{l}\text { Mean } \\
78.17\end{array}$} & \multirow{2}{*}{$\begin{array}{r}\text { SD } \\
43.78\end{array}$} & \multirow{2}{*}{$\begin{array}{r}\text { Total } \\
30\end{array}$} & & & & & & \\
\hline & & & & & & & $21.8 \%$ & $-29.84[-46.42,-13.26]$ & \multicolumn{2}{|c|}{$\longrightarrow$} & \multirow[b]{4}{*}{-} & \\
\hline Kordi 2013, 2014, 2017 & 33.6 & 13.7 & 105 & 42.1 & 17.1 & 105 & $27.7 \%$ & $-8.50[-12.69,-4.31]$ & & $-\frac{1}{2}$ & & \\
\hline Ahmed et al. 2018 & 23.59 & 23.73 & 26 & 31.17 & 27.25 & 31 & $23.8 \%$ & $-7.58[-20.82,5.66]$ & & & & \\
\hline Razali et al., 2017 & 54 & 16.1 & 77 & 38 & 29 & 77 & $26.7 \%$ & $16.00[8.59,23.41]$ & & & & \\
\hline Total $(95 \% \mathrm{Cl})$ & & & 238 & & & 243 & $100.0 \%$ & $-6.41[-22.67,9.86]$ & & & & \\
\hline \multicolumn{9}{|c|}{ Heterogeneity: $\mathrm{Tau}^{2}=243.88 ; \mathrm{Chi}^{2}=42.03, \mathrm{df}=3(\mathrm{P}<0.00001) ; \mathrm{I}^{2}=93 \%$} & -50 & -25 & 25 & 50 \\
\hline \multicolumn{9}{|c|}{ Test for overall effect: $Z=0.77(P=0.44)$} & & Date & Control & \\
\hline
\end{tabular}

electrolytes [23, 25]. Oxytocin and prostaglandins have been widely utilized for ripening of cervix, stimulation of uterine contractions, and induction and stimulation of labor especially when the duration of latent phase of labor has been expanded [41, 42]. Misuse of oxytocin and prostaglandins and insufficient maternal care in labor, can lead to delivery complications [43, 44]. Myometer oxytocin receptors are increasing in the last weeks of pregnancy. Estrogen and progesterone levels change in the 34-35 weeks of pregnancy that these changes could lead to the improvement of irritability of uterine, improvement of responsiveness of uterine to contractor factors, and the improvement of cervical preparation to labor [45]. Therefore, date fruit consumption in last weeks of pregnancy can cause labor induction and stimulation, because date fruit acts on prostaglandin receptors, causes early stimulation of uterine contractions, and improves response to syntocinon if it is necessary [41]. Fatty acids in date palm in addition to production and reservation of energy play important role in the prostaglandins production, and following that, in the reinforcement of uterine muscles [26, 27, 46]. On the other hand, drinking water after consuming date fruit during labor is effective on labor progress and shortens the second and the third stages of labor [47]. As well as date palm can increase antioxidant capacity for $4 \mathrm{~h}$, and following that increases pain tolerance, this results in reduction of the first and the third stages of labor [22, 26]. Also, date fruit has anti-inflammatory and antioxidant properties and it is rich in calcium, serotonin, and tannin, and can play a role in contraction of smooth muscles of uterine $[22,48]$. As mentioned earlier, consumption of date fruit had significantly increased the bishop score and cervical dilatation. Bishop score (that contains cervical dilatation and ...) is known as evaluation criteria of labor progress and the increasing factor of normal vaginal labor $[49,50]$. Lack of preparation of cervix and induction of labor can lead to increase of caesarean section rate and postpartum hemorrhage [51-53]. However, increase of the bishop score and preparation of cervix, can increase normal vaginal labor rate and reduce the caesarean section rate [54]. The low dose of oxytocin causes the improvement of the bishop score and the preparation of cervix [55], thus the consumption of date fruit affects the improvement of the bishop score by increasing the activity of myometer contraction. This is a confirmation of possible hypothesis of oxytocin in date fruit and its

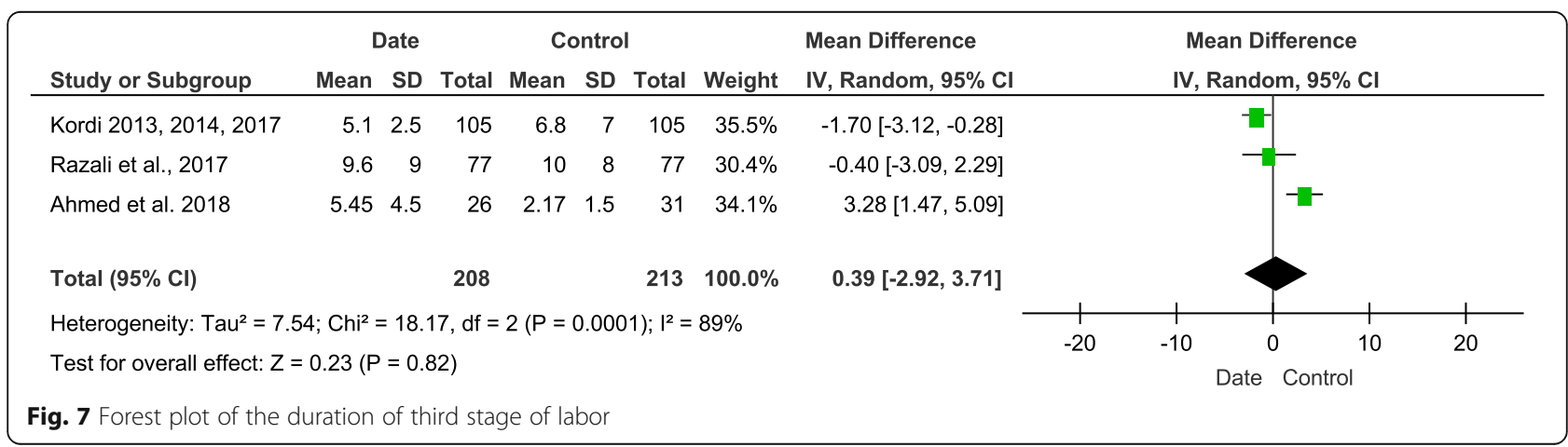




\begin{tabular}{|c|c|c|c|c|c|c|c|c|c|c|c|c|}
\hline \multirow{3}{*}{$\begin{array}{l}\text { Study or Subgroup } \\
\text { Kariman } 2015 \text {, Jadidi } 2015\end{array}$} & \multicolumn{3}{|c|}{ Date } & \multicolumn{3}{|c|}{ Control } & \multirow[b]{2}{*}{ Weight } & \multirow{2}{*}{$\begin{array}{l}\text { Mean Difference } \\
\text { IV, Random, } 95 \% \mathrm{CI}\end{array}$} & \multirow{2}{*}{\multicolumn{3}{|c|}{$\begin{array}{c}\text { Mean Difference } \\
\text { IV, Random, } 95 \% \mathrm{Cl}\end{array}$}} & \\
\hline & Mean & SD & Total & Mean & SD & Total & & & & & & \\
\hline & 7.3 & 2.7 & 55 & 5.1 & 3.2 & 55 & $27.8 \%$ & $2.20[1.09,3.31]$ & & & & \\
\hline Kordi 2013, 2014, 2017 & 7.67 & 2.28 & 105 & 5.12 & 2.77 & 105 & $72.2 \%$ & $2.55[1.86,3.24]$ & & & & \\
\hline Total $(95 \% \mathrm{Cl})$ & & & 160 & & & 160 & $100.0 \%$ & $2.45[1.87,3.04]$ & & & & \\
\hline \multicolumn{9}{|c|}{ Heterogeneity: $\mathrm{Tau}^{2}=0.00 ; \mathrm{Chi}^{2}=0.28, \mathrm{df}=1(\mathrm{P}=0.60) ; \mathrm{I}^{2}=0 \%$} & -4 & -2 & 2 & 4 \\
\hline \multicolumn{9}{|c|}{ Test for overall effect: $Z=8.24(P<0.00001)$} & \multicolumn{3}{|c|}{ Control Date } & \\
\hline
\end{tabular}

effect on uterine muscle contraction [22, 24, 56]. Also, date fruit contains saturated and unsaturated fatty acids linoleic, oleic, and stearic. Linoleic acid breaks down to the arachidonate, and then to the eicosanoid. The eicosanoids finally convert to the prostaglandins and they improve the preparation of cervix by increasing subserosal fluid and making changes in collagen bands, and they cause the increasing of sensitivity of uterine to oxytocin $[36,48,57]$.

Generally, the mechanism of cervical preparation is unknown; however, changes in levels of estrogen and progesterone, increasing of the prostaglandins production, increasing of myometer sensitivity to oxytocin and prostaglandins, and their interactions are identified to be effective $[45,54]$.

Up to the best of our knowledge, the most common causes of cesarean section are abnormal progress of labor and non-effective contractions of uterine [11, 12, 16]. Lack of eating energizer foods during labor lead to the increasing of non-effective contractions of uterine and following that increasing of the augmented delivery and increasing the cesarean section rate [20]. Limited reserves of glycogen and body fluids in pregnant women that have limited consumption of food and liquids during labor can cause low perfusion and low nutrition of uterine, which can be followed by abnormal labor progress, prolonged labor, and the increasing rate of cesarean section [36].

\section{Limitations}

One of the limitations of this study was the lack of specified standard for the kind and the amount of date fruit that must be consumed to bring positive effects on labor progression and cervix preparation. Also, it was not determined that, how long at what intervals of consumption of date fruit is needed to energy supply during labor, reduce the cesarean section rate and promotion of labor outcomes.

Another limitation of this study was the high risk of bias in performed studies. Especially, due to the methods of studies and using the date palm fruit in the studies, blinding of participants and researchers was not possible. Therefore, for this reason, performance bias was raised in included studies. Furthermore, none of these studies had outcome assessor blinding.

The other limitation of this study was the unknown time of intervention and duration of intervention in the most studies.

\section{Conclusion}

Despite widespread utilizing of date palm, there is not enough clinical evidence to support the clinical effects,

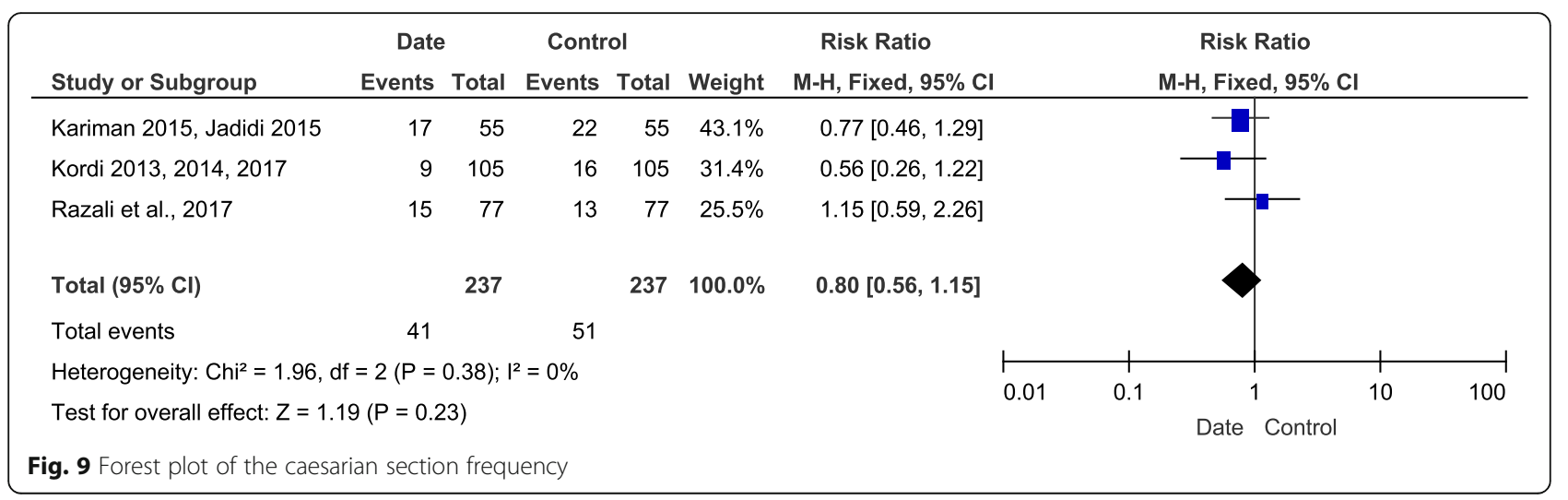


which were mentioned in review articles and traditional medical systems. Based on this study result, date fruit can reduce the duration of active phase and improve the bishop score. The growing trend of recent studies about date palm provides scientific rationale for date palm clinical abilities; however, due to from the low to mediate quality of the studies, it seems that the other studies are needed to prove these results better than this.

\section{Supplementary information}

Supplementary information accompanies this paper at https://doi.org/10. 1186/s12884-020-02915-x.

Additional file 1. Appendix 1: Sample search strategy used for PubMed.

Additional file 2. Appendices 2-6: Forest plots of sensitivity analysis.

Additional file 3. Appendices $8-10$ : Forest plots of subgroup analysis

\section{Abbreviations}

WHO: World health organization; IVF: in vitro fertilization; IUI: Intrauterine insemination; Kcal: Kilo calories; PRISMA: Preferred reporting items for systematic reviews and meta-analyses; SID: Scientific Information Database; IRCT: Iranian Registry of Clinical Trials; EAGLE: European Association for Grey Literature Exploitation; HMIC: Health Care Management Information Consortium; RR: Risk ratio; MD: Mean difference

\section{Acknowledgements}

We would like to thank Dr. Parviz Mohammad Salahi for Literary editing of this paper.

\section{Authors' contributions}

ABK performed initial search of databases and was a major contributor in writing the manuscript. AE and RBN reviewed studies to investigate eligibility criteria. MM regulated methods and performed meta-analysis. MM and $\mathrm{AE}$ supervised writing of the manuscript. All authors read and approved the final manuscript.

\section{Authors' information}

ABK: MD, PhD candidate of Traditional Persian Medicine, Faculty of Traditional Persian Medicine, Tabriz University of Medical Sciences, Tabriz, Iran.

AE: MD, Associate Professor of orthopedic surgery department of faculty of medicine and researcher of shohada hospital, Tabriz University of Medical Sciences, Tabriz, Iran.

MM: PhD, Associate Professor of midwifery department of faculty of nursing and midwifery and researcher of al-zahra and talegani hospitals, Tabriz University of Medical Sciences, Tabriz, Iran.

RBN: MD, PhD candidate of Traditional Persian Medicine, Faculty of Traditional Persian Medicine, Tabriz University of Medical Sciences, Tabriz, Iran

\section{Funding}

This research was supported by Tabriz University of Medical Sciences financially as the one of the papers for PhD thesis (Alireza Bagherzadeh Karimi, no. 15) at faculty of Traditional Persian Medicine at Tabriz University of Medical Sciences. The funding body had no role in study design, data collection and analysis, decision to publish, or preparation of the manuscript.

\section{Availability of data and materials}

All data generated during this study are included in this article, tables, figures and its supplementary information files.

Link/references of databases used in this study: www.clinicalkey.com, www. embase.com, www.scopus.com, www.ncbi.nlm.nih.gov/pubmed, www. webofknowledge.com, www.sid.ir, www.irct.ir, www.scholar.google.com The public access of PubMed, Google Scholar, Scientific Information Database (SID), and IRCT (Iranian Registry of Clinical Trials) are open but Scopus, Web of Knowledge, Clinical Keys, and Embase are close. We used institutional access of Tabriz University of Medical Sciences for these databases.

\section{Ethics approval and consent to participate \\ Not applicable.}

\section{Consent for publication}

Not applicable.

\section{Competing interests}

The authors declare that they have no competing interests.

\section{Author details}

'Department of Persian Medicine, School of Traditional Medicine, Tabriz University of Medical Sciences, Tabriz, Iran. ${ }^{2}$ School of Medicine, Tabriz University of Medical Sciences, Tabriz, Iran. ${ }^{3}$ Midwifery Department, Social Determinants of Health Research Center, Tabriz University of Medical Sciences, Tabriz, Iran.

Received: 16 August 2019 Accepted: 30 March 2020

Published online: 14 April 2020

\section{References}

1. Bick D. Caesarean section. Clinical guideline. National Collaborating Centre for Women's and Children's health: commissioned by the National Institute for clinical excellence. Worldviews Evid-Based Nurs. 2004;1(3):198-9..

2. Althabe F, Sosa C, Belizan JM, Gibbons L, Jacquerioz F, Bergel E. Cesarean section rates and maternal and neonatal mortality in low, medium, and high-income countries: an ecological study. Birth. 2006;33:270-7.

3. Omani-Samani R, Almasi-Hashiani A, Safiri S, Rezaeinejad M, Shokri F, Morasae EK, et al. Why caesarean is more unequally concentrated among better-off people in Tehran? A concentration index decomposition approach. J Epidemiol Community Health. 2019;73(2):182-7.

4. WHO. WHO Global Survey on Maternal and Prenatal Health: Project no. A25176 Operational Manual. https://www.who.int/reproductivehealth/ topics/maternal_perinatal/globalsurvey/en/. Accessed 2004

5. Pirjani $R$, Afrakhteh $M$, Sepidarkish $M$, Nariman $S$, Shirazi M, Moini $A$, et al. 'Elective caesarean section at 38-39 weeks gestation compared to> 39 weeks on neonatal outcomes: a prospective cohort study. BMC Pregnancy Childbirth. 2018;18(1):140.

6. Linton A, Peterson MR, Williams TV. Effects of maternal characteristics on cesarean delivery rates among U.S. Department of Defense healthcare beneciaries, 1996-2002. Birth. 2004;31:3-11.

7. Al-Mufti R, McCarthy A, Fisk NM. Obstetrician's personal choice and mode of delivery. Lancet. 1996;347:544.

8. Wu JM, Hundley AF, Visco AG. Elective primary cesarean delivery: attitudes of urogynecology and maternal-fetal medicine specialists. Obstet Gynecol. 2005:105:301-6.

9. Cotzias CS, Paterson-Brown S, Fisk NM. Obstetricians say yes to maternal request for elective cesarean section: a survey of current opinion. Eur J Obstet Gynecol Reprod Biol. 2001;97:15-6.

10. Porreco RP, Thorp JA. The cesarean birth epidemic: trends, causes, and solutions. Am J Obstet Gynecol. 1996;175:369-74.

11. Hammamy E, Arulkumarans S. Poor progress of labour. Curr Obstet Gynaecol. 2005;15(1):1-8

12. Simkin P, Ancheta RS. The labor progress handbook: early interventions to prevent and treat dystocia. 2nd ed. Oxford: Blackwell; 2005.

13. World Health Organization. Maternal and Newborn Health/Safe Motherhood Unit. Care in normal birth: a practical guide. 1996. http://www.who.int/ maternal_child_adolescent/documents/who_frh_msm_9624/en/.Accessed 15 Aug 1996.

14. Gulmezoglu AM, Crowther CA, Middleton P, Heatley E. Induction of labour for improving birth outcomes for women at or beyond term. Cochrane Database Syst Rev. 2012;6:CD004945. https://doi.org/10.1002/14651858. CD004945.pub3.

15. Dowswell T, Kelly A, Livio S, Norman J, Alfirevic Z. Different methods for the induction of labour in outpatient settings. Cochrane Database Syst Rev. 2010;8:CD007701.

16. Tranmer JE, Hodnett ED, Hannah ME, Stevens BJ. The effect of unrestricted oral carbohydrate intake on labor progress. J Obstet Gynecol Neonatal Nurs. 2005;34(3):319-28. 
17. American College of Nurse Midwives. Intrapartum nutrition: clinical bulletin. 1999;3. http://www.midwife.org. Accessed Jun 8, 2007.

18. WHO. General aspects of care in labor (part2): nutrition. http://www.who.int/ reproductive_health/Publications/MSM/_96_24/Care_in_normal_birth_ Practical_guide. Accessed Mar 7, 2006.

19. Sleutel M, Golden SS. Fasting in labor: relic or requirement. J Obstet Gynecol Neonatal Nurs. 1999;28(5):507-12.

20. Scheepers HC, Thans MC, de Jong PA, Essed GG, Le Cessie S, Kanhai HH. Eating and drinking in labor: the influence of caregiver advice on women behavior. Birth. 2001;28(2):119-23.

21. Al-Farsi MA, Lee CY. Nutritional and functional properties of dates: a review. Crit Rev Food Sci Nutr. 2008;48(10):877-87.

22. Al-Shahib W, Marshall RJ. The fruit of the date palm: it's possible use as the best food for the future? Int J Food SciNutr. 2003;54(4):247-59.

23. Alaei H, Pakdaman M. The nutrition therapy from the holy Quran and science perspective. Specialized J Quran and Sci. 2009;3(5):83-112.

24. Oktar A. Foods mentioned in the Qur'an. 2012. http://www. miraclessofthequran.com/food. Accessed 2012

25. Amer WM. Alckemy in Islamic times: history of botany Part1. 2006. http:// www.Levity.Com/alckemy/islam08. Accessed Jun 5, 2006.

26. Baliga MS, Baliga BRV, Kandathil SM, Bhat HP, Vayalil PK. A review of the chemistry and pharmacology of the date fruits (Phoenix dactylifera L.). Food Res Int. 2011:44:1812e1822.

27. Odent M. Laboring women are not marathon runners. Midwifery Today Childbirth Educ. 1994:31:23e25.

28. Makarem SN. Tafsirenemooneh, vol. 13. Ghom: Darolketabe Al-Eslamiyeh; 2008.

29. Jorjani ME. Zakhireye Kharazm Shahi Qom. Iran: Ehya'e tibbe tabiee; 2012.

30. Briggs JP. Complementary, Alternative, and Integrative Health Practice. In: Kasper DL, Fauci AS, Hauser SL, Longo DL, Jameson JL, Loscalzo J, editors. Harrison's principles of internal medicine. 1. New York: Mcgraw-hill; 2015. p $14 \mathrm{e}-1$.

31. Moini, Jazani A, Hamdi K, Tansaz M, Nazemiyeh H, Sadeghi Bazargani H, Fazljou SMB, Nasimi Doost R. Herbal Medicine for Oligomenorrhea and Amenorrhea: A Systematic Review of Ancient and Conventional Medicine. Biomed Res Int. 2018:2018:1-22.

32. Nasiri M, Gheibi Z, Miri A, Rahmani J, Asadi M, Sadeghi O, et al. Effects of consuming date fruits (Phoenix dactylifera Linn) on gestation, labor, and delivery: an updated systematic review and meta-analysis of clinical trials. Complement Ther Med. 2019:45:71-84.

33. Kordi M, Aghaei Meybodi F, Tara F, Nemati M, Taghi SM. The effect of late pregnancy consumption of date fruit on cervical ripening in nulliparous women. Midwifery Reprod Health. 2014;2(3):150-6.

34. Kordi M, Meybodi FA, Tara F, Fakari FR, Nemati M, Shakeri M. Effect of dates in late pregnancy on the duration of labor in nulliparous women. Iran J Nurs Midwifery Res. 2017;22(5):383.

35. Kordi M, Aghaei Meybodi F, Tara F, Nematy M, Shakeri MT. The effect of date consumption in late pregnancy on the onset of labor in nulliparous women. Iranian J Obstetrics Gynecol Infertil. 2013;16(77):9-15.

36. Kariman N, Jadidi MY, Sang SJB, Rahbar N, Afrakhteh M, Lary H. The effect of consumption date fruit on cervical ripening and delivery outcomes. Pajoohande. 2015;20(2):72-7.

37. Jadidi MY, Sang SJB, Kariman N, Lari H. The effect of date fruit consumption on spontaneous labor. J Res Religion Health. 2015;1(3):4-10.

38. Kordi M, Nasiri N, Safarian M, Esmaili H, Shadjuo K. The effect of oral honeydate syrup intake during labor on labor progress of nulliparous women. Iranian J Obstetrics Gynecol Infertil. 2010;13(2):23-30.

39. Ahmed IE, Mirghani HO, Mesaik MA, Ibrahim YM, Amin TQ. Effects of date fruit consumption on labour and vaginal delivery in Tabuk, KSA. J Taibah Univ Med Sci. 2018;13(6):557-63.

40. Razali N, Mohd Nahwari SH, Sulaiman S, Hassan J. Date fruit consumption at term: effect on length of gestation, labour and delivery. J Obstet Gynaecol. 2017;37(5):595-600.

41. Hayes EJ, Weinstein L. Improving patient safety and uniformity of care by a standardized regimen for the use of oxytocin. Am J Obstetrics Gynecol. 2007;198:622 e1-e7.

42. Svardby K, Nordstrom L, Sellstrom E. Primiparas with or without oxytocin augmentation: a prospective descriptive study. J Clin Nurs. 2007;16:179-84

43. Jeffery P, Das A, Dasgupta J, Jeffery R. Unmonitored intrapartum oxytocin use in home deliveries: evidence from Uttar Pradesh, India. Reprod Health Matters. 2007;15:172-8.
44. Khalil K, Cherine M, Elnoury A, Sholkamy H, Breebaart M, Hassanein N. Labor augmentation in an Egyptian teachinghospital. Int J Gynaecol Obstet. 2004; 85:74-80.

45. Asgarisafdar A, DaghighKia H, Farhadi R. Physiology of parturition. Int J Adv Biol Biomed Res. 2013;1(3):214-21.

46. Speroff L, Fritz MA. Clinical gynaecologic endocrinology and infertility. New York: Lippincott Williams \& Wilkins; 2005.

47. Al-Dossari AR, Ahmad ER, Al Qahtani NH. Effect of eating dates and drinking water versus IV fluids during labor on labor and neonatal outcomes. IOSR J Nurs Health Sci. 2017;6(4):86e94.

48. Khadem N, Sharaphy A, Latifnejad R, Hammod N, Ibrahimzadeh S. Comparing the efficacy of dates and oxytocin in the management of postpartumhemorrhage. Shiraz EMed J. 2007;8:64e71 http://emedicalj.portal. tools.

49. Ricci SS, Kyle T. Maternity and Pediatric Nursing. 2nd ed. Philadelpia: Lippincott Williams \& Wilkins; 2009. p. 654-6.

50. Tan TC, Yan SY, Chua TM, Biswas A, Chong YS. A randomised controlled trial of lowdose misoprostol and dinoprostone vaginal pessaries for cervical priming. BJOG Int J Obstet Gynaecol. 2010;117(10):1270-7.

51. Pennell CE, Henderson JJ, O'Neill MJ, McCleery S, Doherty DA, Dickinson JE. Induction of labour in nulliparous women with an unfavorable cervix: a randomized controlled trial comparing double and single balloon catheters and PGE gel. BJOG Int J Obstet Gynaecol. 2009;116(11):1443-52.

52. Guerra GV, Cecatt JG, Souza JP, Faundes A, Morais SS, Gulmezoglu AM, et al. Factors and outcomes associated with the induction of labour in Latin America. Bull World Health Organ. 2011:89:657-65.

53. Al-Shaikh GK, Wahabi HA, Fayed AA, Esmaeil SA, Al-Malki. Factors associated with successful induction of labor. Saudi Med J. 2012;33(3):298-303.

54. Cunningham GF, Kenneth LJ, Steven BL, John HC, Gilstrap III, Larry C, Katharine WD. Williams obstetrics. 23 nded. New York: Mc Graw Hill; 2010.

55. Kashanian M, Parashi Sh, Nikfarjam S. Comparison the effect of two methods of intracervical Foley catheter insertion and Low-dose oxytocin infusion to improve Bishop Score in term pregnancies. Urmia Med J. 2007; 18(3):562-66.

56. Mojahed Sh, Aflatoonian A, Khadem N, Dehghani Firoozabadi R, Karimi M. The evaluation of the effect of half-ripe date on bleeding after vaginal delivery. Scientific Research Journal of Yazd Shahid Sadooghi University of Medical Sciences. 2012;20(2):159-66.

57. Yazdani Sh, Javadian M, Boozari Z, Ghanbari S. Comparing the efficacy ofintracervical Foley catheter with vaginal prostaglandin suppository for cervicalripening before delivery induction. Journal of Mazandaran University of Medical Sciences. 2010;20(79):56-61.

\section{Publisher's Note}

Springer Nature remains neutral with regard to jurisdictional claims in published maps and institutional affiliations.

Ready to submit your research? Choose BMC and benefit from:

- fast, convenient online submission

- thorough peer review by experienced researchers in your field

- rapid publication on acceptance

- support for research data, including large and complex data types

- gold Open Access which fosters wider collaboration and increased citations

- maximum visibility for your research: over $100 \mathrm{M}$ website views per year

At $\mathrm{BMC}$, research is always in progress.

Learn more biomedcentral.com/submissions 